Musen (KS II, 329-333) einen Augenzeugenbericht über die gewaltsamen Übergriffe liefert.

Döblins journalistische Arbeiten der 1920er Jahre sind aber nicht nur als lebendige Zeitdokumente interessant und wertvoll, sondern eben auch in ästhetischer Hinsicht - als bislang kaum wahrgenommene Beiträge zur Flaneurprosa in der Tradition Charles Baudelaires, wie sie im deutschsprachigen Raum vor allem von Robert Walser, Franz Hessel und Walter Benjamin verfasst wurde.

\section{Epos contra Essay}

Döblins essayistische Publizistik entwickelte in den Zwischenkriegsjahren insofern ein Eigenleben, als er eine deutliche Trennlinie zur Epik zog. Als solche verstand er die von der »Souveränität der Phantasie« getragene Dichtung, die ihrerseits »im klaren Gegensatz zur zweckgetragenen rationalen Schriftstellerei« (SÄPL 206) stehe (vgl. zum diskursiven Umfeld: Wachter 2009). Er räumt zwar verschiedentlich ein, dass »Gesinnung «, begriffen als politischer oder ethischer Standpunkt, durchaus einen »künstlerischen Prozeß « einleiten, aber das Kunstwerk auch gefährden und $\mathrm{zu}$ einem fragwürdigen »Tendenzwerk « (SÄPL 207) machen könne. Diese Abwehrhaltung manifestiert sich in seinem programmatischen Essay Reform des Romans aus dem Jahre 1919, in dem er sich erstmals deutlich gegen Adaptionen und Transformationen essayistischer Schreibformen in episch-narrativen Texten wendet. Ausgangspunkt seiner Kritik ist Otto Flakes Roman Die Stadt des Hirns, mit dem der Autor laut Vorrede "Denken, Verstand, Reflexion für die Epik erobern" (SÄPL 138) wolle - ein Vorhaben, das aus Sicht Döblins jedoch zur Umfunktionierung des Romans »als Rednerbühne« (ebd. 151) geführt habe. Diese Haltung widerspricht seiner Zielsetzung, den Roman »als `Dichtung « und `Kunstwerk « im emphatischen Sinn [zu] erneuern und als >modernes Epos« [zu] gestalten« (Kiesel 2004, 309).

Döblin polemisiert auch in der Folgezeit immer wieder gegen eine solche Öffnung des Romans hin zum Reflexiv-Philosophischen und Essayistischen (vgl. KS II, 166) bzw. gegen den »Mißbrauch des Romans für essayistische Versuche (KS III, 96), da diese zu dem beigetragen hätten, was er 1928 - mit Seitenhieben auf die neusachliche Literatur und einige ihrer ästhetischen Postulate - als das »Herabsinken in das Praktische, in das Nützlich-Begreifliche« und als »zivilisatorische Entartung des Kunstwerks« (SÄPL 206) bezeichnet. Noch pointierter ist eine Äußerung von 1948, in der er im Rückblick auf dominante literarische Strömungen der 1920er Jahre sogar die »feuilletonistische, essayistische Degeneration des Romans" (SLW 312) anprangert. Essay und Roman bzw. Epos bilden also für Döblin zwei unterschiedliche literarische Ausdrucksformen und Genres, deren Vermischung er - in deutlicher Abgrenzung zu Autoren wie Thomas Mann, Robert Musil, Hermann Broch u. a. (vgl. Schärf 1999, 229-248) - entschieden ablehnt. 